\title{
Optimal seismic response using a Passive Tuned Mass Damper Inerter (TMDI)
}

\author{
Djerouni S ${ }^{1,}{ }^{*}$, Ounis $\mathrm{A}^{1}$, Athamnia $\mathrm{B}^{2}$, Charrouf ME ${ }^{1}$, Abdeddaim $\mathrm{M}^{1}$, Djedoui $\mathrm{N}^{1}$
}

1 Department of civil engineering and hydraulics, Mohamed Khider University, Biskra, Algeria.

2 Department of civil engineering „, Larbi Tébessi University, Tebessa, Algeria.

Corresponding Author: djerouni100@gmail.com

Received: 29-01-2020

Accepted: 10-04-2020

\begin{abstract}
The latest earthquakes history shows that resistant conception, safe and economical structures are a daily challenge for structural engineers. Among the newest vibration control devices figures the inerter which is a device which can develop a large fictive mass (it consists of a mass amplification effect) using rotational inertia. In this research work, the effectiveness of a traditional passive tuned mass damper (TMD) is compared with a tuned mass damper inerter (TMDI) which consists generally of tuned mass damper coupled with an Inerter. Both devices are used to control a base-isolated structure vibration submitted to several seismic records. In This study, a base-isolated structure of six stories (6 DOF) was equipped with (TMD) and (TMDI) and a time history analysis were performed under different earthquake records (El Centro, Kobe, Kocaeli). The mathematical model of the building is established in MATLAB Simulink. The simulation results illustrated he robustness, performance and effectiveness of the structure equipped with a (TMDI). The dynamical parameters of interest were base and top displacement as well as the base shear force and peak inerter force produced.
\end{abstract}

Keywords: Vibration control, Hybrid system, passive system, tuned mass damper inerter, inertance, inerter.

\section{Introduction}

The research of an effective vibration suppression systems such as (passive, active, semi-active and hybrid ) has been a daily challenge in the civil engineering area, mainly for mitigating the dynamic vibration and decreasing the effects of the damage due to natural phenomena, such as earthquakes and winds or several excitations (Brzeski et al., 2015).

The base-isolated passive control can be used to reduce the buildings response. Hence, achieve buildings protection from any natural damages (earthquakes, winds).

Therefore, the base-isolation is one of the oldest aseismic design strategies, based on decoupling the super-structure from the ground movement to decrease the effects of different excitations and to mitigate the forces being transmitted to the building from the ground for a natural frequency that is much longer than the fundamental frequency of the ground movement.

On the other hand, a long natural frequency mostly produced in small ground acceleration, it will results in large displacement at the base-isolated ground (building's move such as a rigid block). Hence, lowering or reducing these large displacements is an essential problem or case to consider when base-isolated is adjacent to other buildings.

Further, to control base-isolated structure acceleration without producing a significant rise in displacement, supplemental seismic control strategies can be used (Shi et al., 2018; Djerouni et al., 2019). 
The hybrid control is usually a result of two different control systems combinations, such as combining the structural base isolator with other devices such as MR damper, TMD, TLD, TMDI, and TID.

In recent years, the most common devices using in the hybrid control system are a tuned mass damper connection (TMD) at lowest or at roof with a base-isolated structure (Tsai, 1995; Hadi et al., 1998; Palazzo and Petti, 1999; Djedoui and Ounis, 2014; De Domenico and Ricciardi, 2018; Elias and Matsagar, 2018).

The classic passive tuned mass damper (TMD) is one of the most effective, performance devices characterized by a linear damper, a mass, and a spring installed or attached in high-rise buildings at the roof usually (Den Hartog, 1929).

Furthermore, passive system TMDs are centered on the rule of energy reduction in the nature of oscillation of the mass damper and the induction of mass inertial force in the opposite phase of the applied counter force to the building. In addition, the natural vibration mode of the classic TMD is tuned to the first natural vibration mode of the structure. However, as for example the skyscraper (Taipei 101 in Taiwan 508 meters) (Fig 1) is equipped with 730 ton TMD acting like a large pendulum to counteract (counterforce opposing) the building's movement decreasing sway due to wind by 30 to $40 \%$ ) (Djerouni et al., 2019).

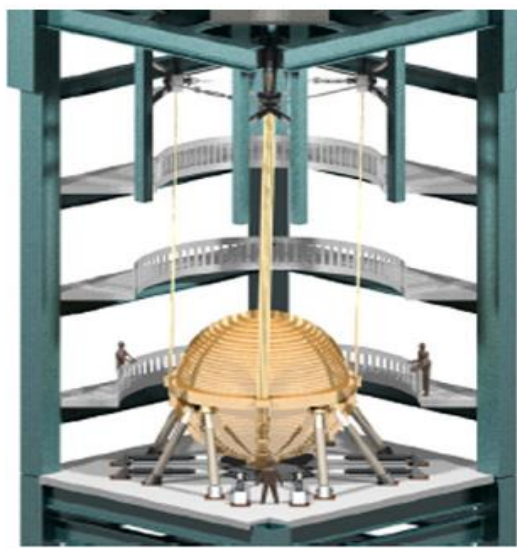

Fig 1. TMD giant pendulum installed at the top in Taipei 101 (Taiwan 508 meters) (Bekdaş and Nigdeli, 2011).

The last recent research shows that an adequate hybrid control system can decrease the displacement generated using the base-isolated from (15\% to $25 \%$ ), a (TMD) mounted having a mass ratio offer of $5 \%$ less or more of the building total mass.

A limitation about passive TMDs is related to the (TMD) mass, which may be unbelievable large or big, thus needing a large space/clearance in the building to confirm the displacement request of this additional or supplemental mass, occasionally same overriding the maximum acceptable displacement of the base-isolated (De Domenico and Ricciardi, 2018; Charrouf et al., 2019).

In a try to overcome the weakness of both the base isolator and TMD, this paper uses a new small device namely " inerter " established with mass augmentation effect connected in passive (TMD) for enhancing the performance of this (TMD) with less mass. Hence, this paper presents a combination of three (03) hybrid structures with different devices mounted on:

- Base isolated structure without any device $\left(\mathrm{L}_{1}\right)$

- Base isolated structure with TMD connected at the bottom $\left(\mathrm{L}_{2}\right)$

- Base isolated structure with TMDI connected at the bottom $\left(\mathrm{L}_{3}\right)$

(Using the same apparent mass or physical /weight of the TMD). 


\subsection{Review of the tuned mass damper inerter (TMDI)}

The first suggestion to use an inerter was in the domain of racing car (formula 1 car's) under name J-damper (Fig 2) by Pr. Malcolm Smith and his research team from Cambridge University in 2002 (De Domenico and Ricciardi, 2018; Charrouf et al., 2019). The perfect inerter is based on a mechanism system employing in a collective organization a rack, some gears, and pinions, connected to turning flywheels. This small device creates a large force resisting between its terminals, its force is proportional to the relative acceleration. After the successful use of an inerter in the domain of car racing, several numbers of studies on other possible applications of inerter in the structural system, buildings, vibration suppression were performed ( $\mathrm{Hu}$ and Chen, 2015) .

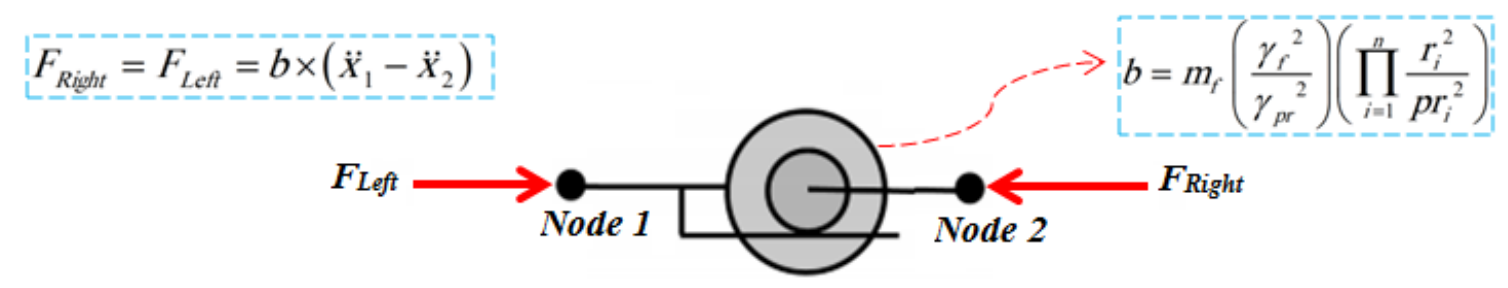

Fig 2. Ideal inerter with two poles (Barredo et al., 2019).

Tuned mass damper inerter (TMDI) creates a conventional generalization passive tuned mass damper (TMD) mass, spring, damper, and inerter.TMDI getting the attention of the researcher (Giaralis and Taflanidis, 2015). In this last study, the TMD Inerter enables beneficial in reducing vibration motion from earthquakes and winds that advantage dubbed inertance (the mass effect of TMDI) which can reach of size to 200 times higher than its apparent mass established (Brzeski et al., 2015; Giaralis and Taflanidis, 2015; Hu and Chen, 2015; De Domenico and Ricciardi, 2018; Charrouf et al., 2019; Jia et al., 2019).

\section{Equation of motion}

Using d'Alembert's law, the principal equations of combined motion n DOF system are shown in equation (1), while, $X(t), \dot{X}(t)$ and $\ddot{X}(t)$ are the system displacement, velocity, and acceleration vectors, can be easily written in matrix form as follows (Brzeski et al., 2015; Giaralis and Taflanidis, Hu and Chen, 2015; Abdeddaim et al., 2018; De Domenico and Ricciardi, 2018; Charrouf et al., 2019; Jia et al., 2019):

$[M] \ddot{X}(t)+[C] \dot{X}(t)+[K] X(t)=-[M]\{\Lambda\} \ddot{X}_{g}(t)$

Where $[M]$ is the masse matrix, $[K]$ the stiffness matrix and $[C]$ the damping matrix of the structure. While the ground acceleration force distribution vector is expressed as

$\{\Lambda\}=\left[\begin{array}{lll}1 & 1 & 1\end{array}\right]^{T}$

\section{Numerical study}

To demonstrate the performance, robustness, and adequacy of the novel passive Tuned Mass Damper Inerter, the three (03) structures $\left(\mathrm{L}_{1}\right),\left(\mathrm{L}_{2}\right),\left(\mathrm{L}_{3}\right)$ (Benchmark Model) taken from paper Deastra et al. (2018), presented above for combining the response of its (03) devices (baseisolated, base-isolated \& TMD, base-isolated \& TMDI) installed in MDOF primary structure.

The following (Table1) shows the properties of the structure and base isolator used in his paper. Otherwise, the tuning of the frequency of TMD \& TMDI is tuned to the first frequency (first mode) of a base-isolated structure $\left(\mathrm{L}_{1}\right)$. 
Table 1. Properties of the considered base isolator system and main structure (Deastra et al., 2018).

\begin{tabular}{|c|c|c|c|}
\hline Floor & Mass ( Ton ) & Stiffness $10^{3}(\mathrm{KN} / \mathrm{m})$ & Damping (KN.s/m) \\
\hline \hline 1 & 3.5 & 35 & 35 \\
\hline. & 3.5 & 35 & 35 \\
\hline 5 & 3.5 & 35 & 35 \\
\hline Base-isolated & 3.5 & 0.21 & 2.66 \\
\hline
\end{tabular}

TMD and TMDI device tuning formulas for calculating and parameters shown in the following table (Table 2).

Table 2. Expressions for optimal tuning with TMD and TMDI for n DOF structure (Marian and Giaralis, 2017).

\begin{tabular}{|c|c|c|}
\hline & Frequency ratio $(v)$ & Damping ratio $\zeta$ ) \\
\hline \hline \multirow{2}{*}{ Force excited TMD $(\beta=0)$} & $\frac{1}{1+\beta+\mu}$ & $\sqrt{\frac{3(\mu+\beta)}{8(1+\mu+\beta)}}$ \\
\hline Force excited TMDI $(\beta \neq 0)$ & & $\sqrt{ }$ \\
\hline
\end{tabular}

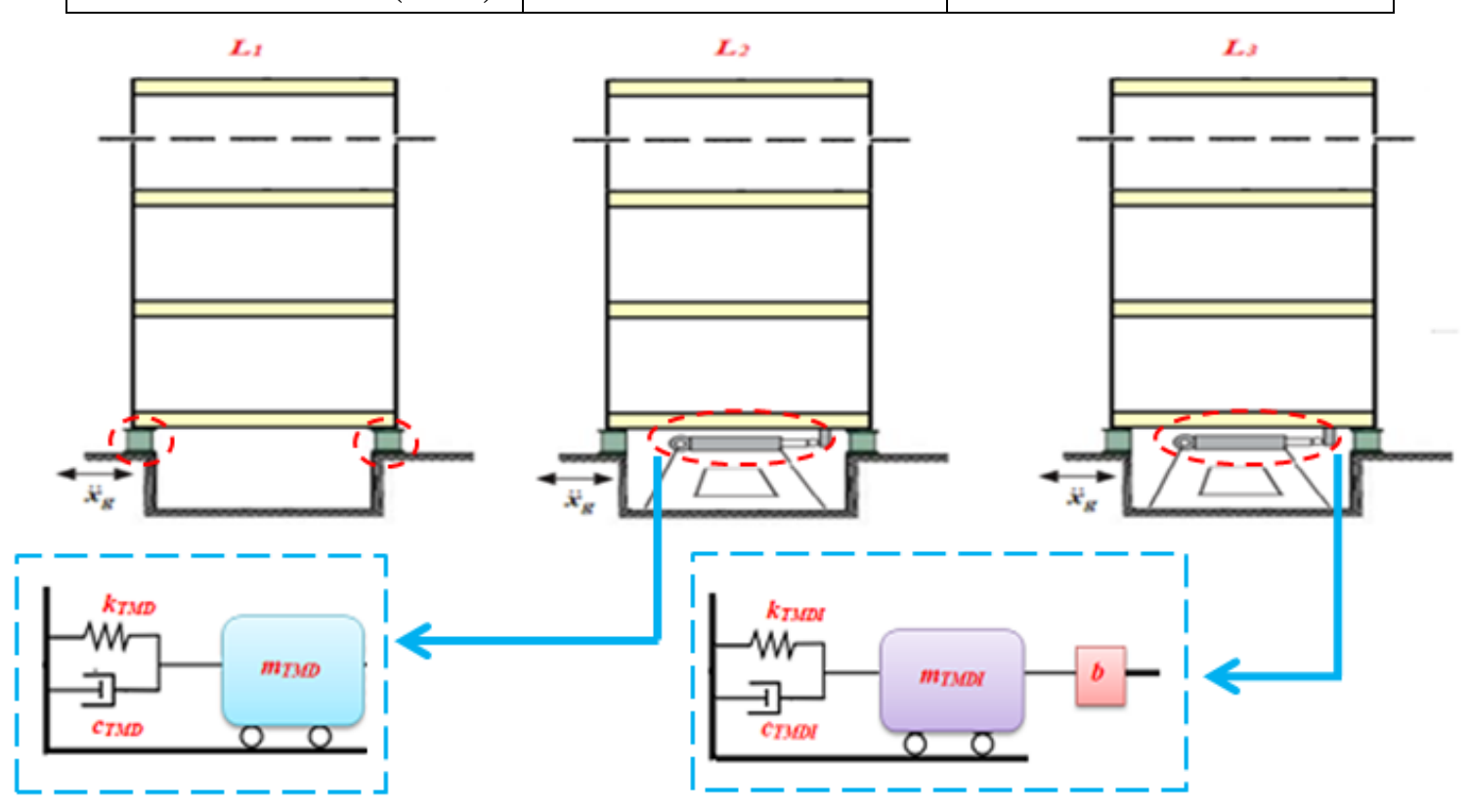

Fig 3. The (03) structures with several passive devices studies

\section{Results and discussion}

The system described in the previous section was considered. The structures are subjected to (El Centro, Kobe, Kocaeli) normalized earthquakes records, with a PGA of 0.3g.

For the three structures $\left(\mathrm{L}_{1}\right),\left(\mathrm{L}_{2}\right),\left(\mathrm{L}_{3}\right)$ proposed configurations, the TMD is tuned using the Den Hartog approach and the TMDI is tuned using Marian and Giaralis (2017) manner demonstrated in (Table 2).

Different strategies were used and results were compared: the TMDI connected between the ground and the base-isolated in structure $\left(\mathrm{L}_{3}\right)$ and TMD placed in the same position of TMDI in structure $\left(\mathrm{L}_{2}\right)$ showed in previous (Fig 3 ).

The responses amount investigated are the maximum displacement of the last story and the first story, the maximum base shear and the peak force inerter between two poles. 
In order to estimate the effectiveness of the hybrid system, a base-isolated structure with a tuned mass damper called $\left(\mathrm{L}_{2}\right)$ and a base-isolated structure with tuned mass damper inerter called $\left(\mathrm{L}_{3}\right)$ are compared with a conventional base-isolated structure called $\left(\mathrm{L}_{1}\right)$ (Benchmark model).

The results in Fig (4-7) show the top displacement, base displacement, maximum base shear, inerter force under (El Centro, Kobe, Kocaeli) earthquakes near-field (NF) and far-field (FF).
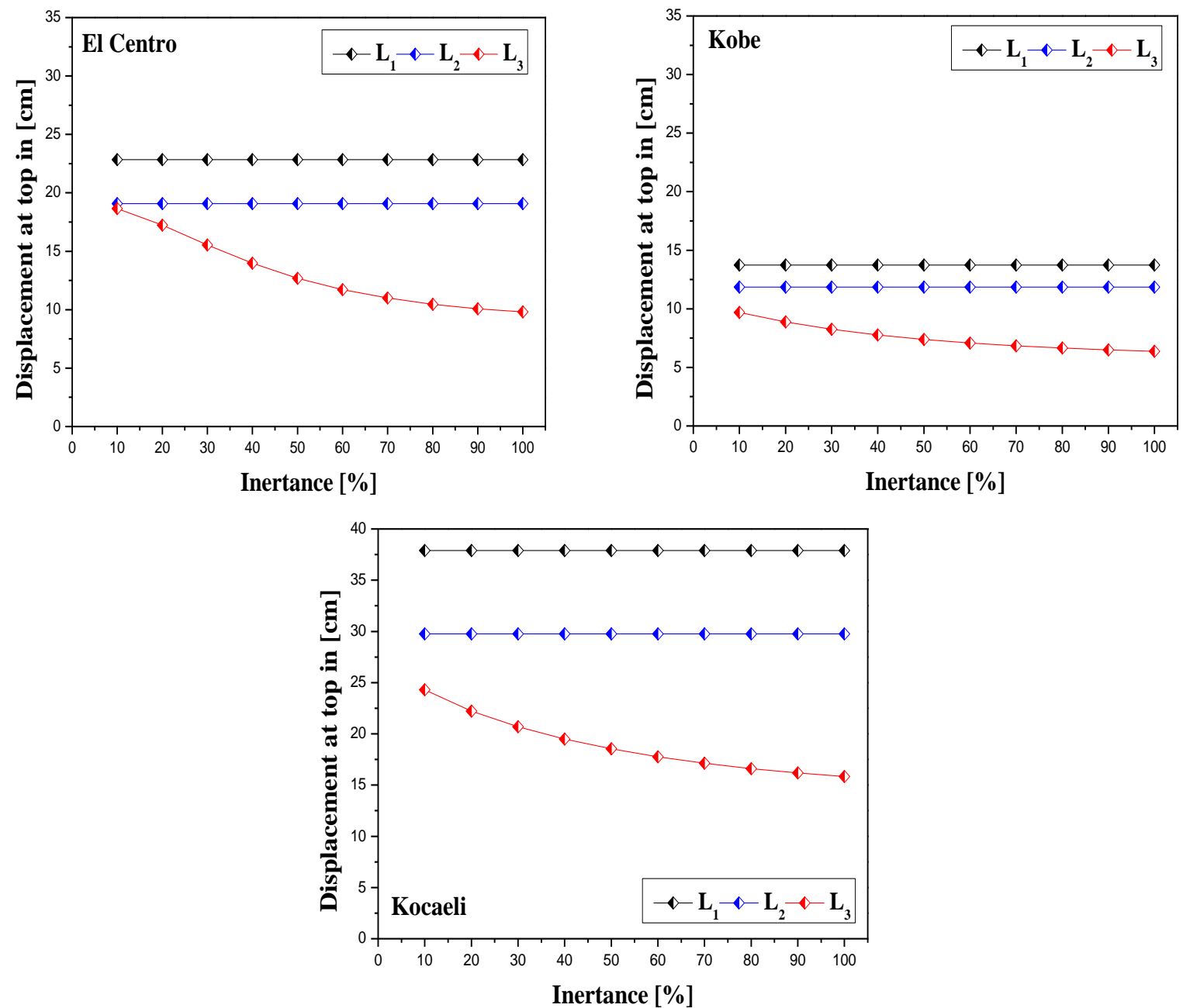

Fig 4. Maximum displacement of the last storey under El Centro, Kobe, Kocaeli earthquakes

Fig 4, shows that top floor displacement in structure $\left(\mathrm{L}_{3}\right)$ is smaller than in structure $\left(\mathrm{L}_{2}\right)$. Otherwise, in structure $\left(\mathrm{L}_{3}\right)$ the TMDI gives maximal inertance values. The fact that the herein considered TMDIs are better suited to suppress floor displacement rather than floor displacements, compared to the TMD.

As can be seen from Fig 4, the response mitigation in peak top floor displacement represents the reduction of (03) structures mentioned earlier $\left(\mathrm{L}_{1}, \mathrm{~L}_{2}, \mathrm{~L}_{3}\right)$ in terms of inertance factor, noted with $\left(\mathrm{L}_{1}\right)$ is $22,831 \mathrm{~cm}$ and $\left(\mathrm{L}_{2}\right)$ is $19,087 \mathrm{~cm}$ and $\left(\mathrm{L}_{3}\right)$ from 18,655 to $9,811 \mathrm{~cm}$ under El Centro earthquake, also $\left(L_{1}\right)$ is $13,747 \mathrm{~cm}$ and $\left(L_{2}\right)$ is $11,853 \mathrm{~cm}$ and $\left(L_{3}\right)$ from 9,681 to 6,376 cm under Kobe earthquake, while $\left(L_{1}\right)$ is $37,893 \mathrm{~cm}$ and $\left(L_{2}\right)$ is $29,767 \mathrm{~cm}$ and $\left(L_{3}\right)$ from 24,294 to 15,829 cm under Kocaeli earthquake.

Fig 4, shows that the top floor displacement in structure $\left(\mathrm{L}_{3}\right)$ is smaller than in structure $\left(\mathrm{L}_{2}\right)$. Accordingly, in structure $\left(\mathrm{L}_{3}\right)$, the TMDI gives maximal and smaller inertance values respectively under El Centro and Kobe earthquake equal to 18,655 cm and 6,376 cm. 
From Fig 5, the novel passive TMD Inerter used in $\left(\mathrm{L}_{3}\right)$ does much better than the passive conventional TMD used in $\left(\mathrm{L}_{2}\right)$ in moderating the peak base floor displacement, improved peak base floor displacement mitigation is accomplished for relatively high inertance values.
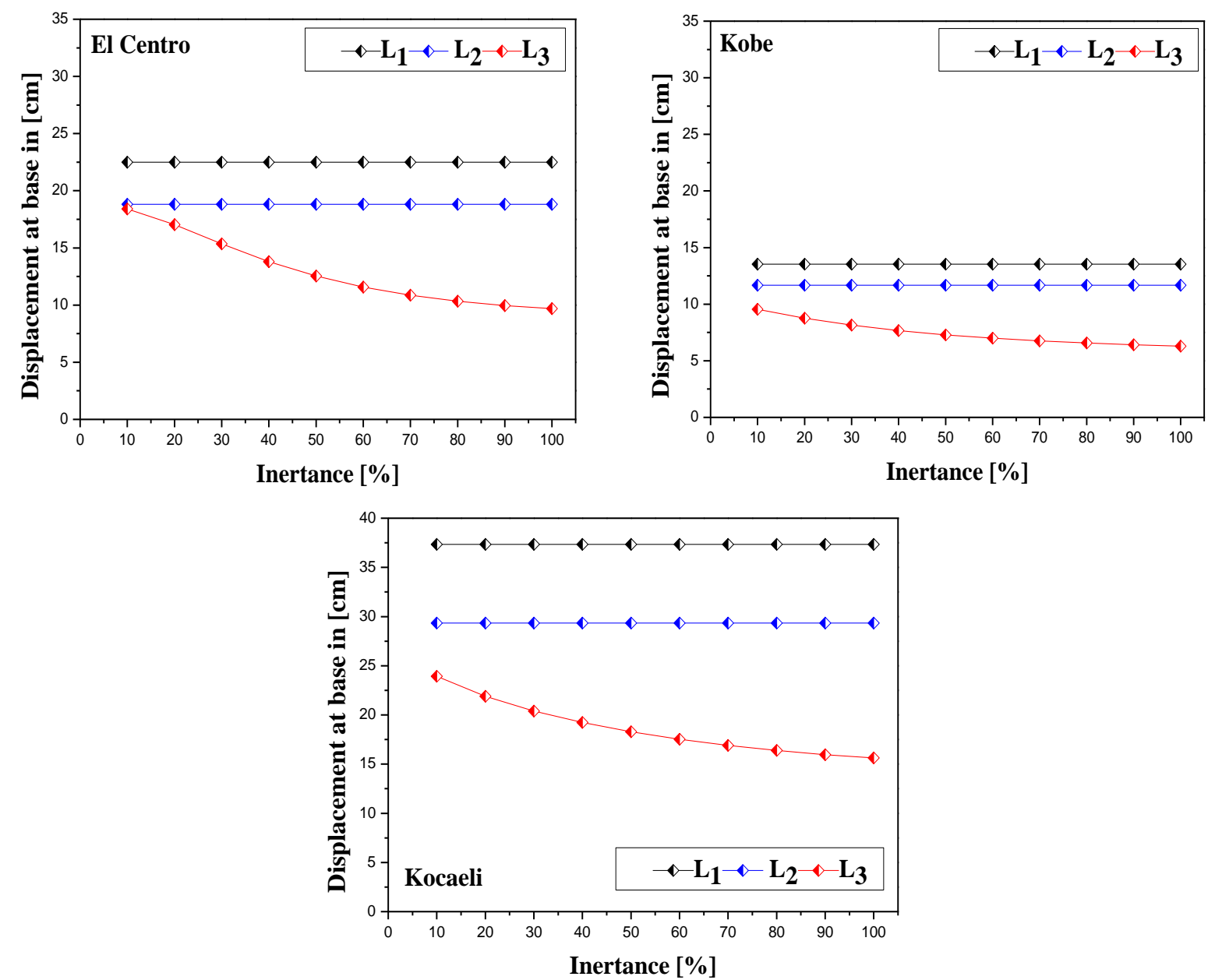

Fig5. Maximum displacement of the first storey under El Centro, Kobe, Kocaeli earthquakes

The fact that the herein considered TMDIs is better suited to suppress floor displacement, compared to the TMD.

As it can be seen from Fig 5, the response reduction in peak base or bottom floor displacement, represents the reduction for the structures mentioned earlier $\left(L_{1}, L_{2}, L_{3}\right)$ in terms of inertance factor: noted $\left(\mathrm{L}_{1}\right)$ is $22,492 \mathrm{~cm}$ and $\left(\mathrm{L}_{2}\right)$ is $18,820 \mathrm{~cm}$ and $\left(\mathrm{L}_{3}\right)$ from 18,417 to $9,686 \mathrm{~cm}$ under El Centro earthquake, also $\left(L_{1}\right)$ is $13,543 \mathrm{~cm}$ and $\left(\mathrm{L}_{2}\right)$ is $11,683 \mathrm{~cm}$ and $\left(\mathrm{L}_{3}\right)$ from 9,544 to $6,292 \mathrm{~cm}$ under Kobe earthquake, while $\left(\mathrm{L}_{1}\right)$ is $37,332 \mathrm{~cm}$ and $\left(\mathrm{L}_{2}\right)$ is $29,341 \mathrm{~cm}$ and $\left(\mathrm{L}_{3}\right)$ from 23,940 to $15,621 \mathrm{~cm}$ under Kocaeli earthquake.

According to Fig 5, the maximum base floor displacement in structure $\left(\mathrm{L}_{3}\right)$ is reduced compared with other structures $\left(\mathrm{L}_{1}\right)$ and $\left(\mathrm{L}_{2}\right)$. Consequently, the maximal and smaller inertance factor value are respectively obtained under Kocaeli and Kobe earthquake by a value equal to 37,233 $\mathrm{cm}$ and $6,292 \mathrm{~cm}$.

From Fig 6, the response reduction in maximum base shear of the (03) buildings is about 52,020 [KN] by $\left(\mathrm{L}_{1}\right), 43,151[\mathrm{KN}]$ by $\left(\mathrm{L}_{2}\right)$, and increasing from 46,903 to 76,119 [KN] by $\left(\mathrm{L}_{3}\right)$ for El Centro earthquake. Also, a reduction of about $29,607[\mathrm{KN}]$ by $\left(\mathrm{L}_{1}\right), 25,628[\mathrm{KN}]$ by $\left(\mathrm{L}_{2}\right)$, a reduction from 23,174 to 20,553 [KN] by $\left(\mathrm{L}_{3}\right)$ for Kobe earthquake. A reduction of about 78,368 
[KN] by $\left(\mathrm{L}_{1}\right), 61,683[\mathrm{KN}]$ by $\left(\mathrm{L}_{2}\right)$, a decrease from 50,998 to 35,187 [KN] by $\left(\mathrm{L}_{3}\right)$ for Kocaeli earthquake.

According to Fig 6, the results show an increase of the maximum base shear force in structure $\left(\mathrm{L}_{3}\right)$ compared to the structure $\left(\mathrm{L}_{1}\right)$ and structure $\left(\mathrm{L}_{2}\right)$ by the maximum value equal to 78,368 [KN] under Kobe earthquake.
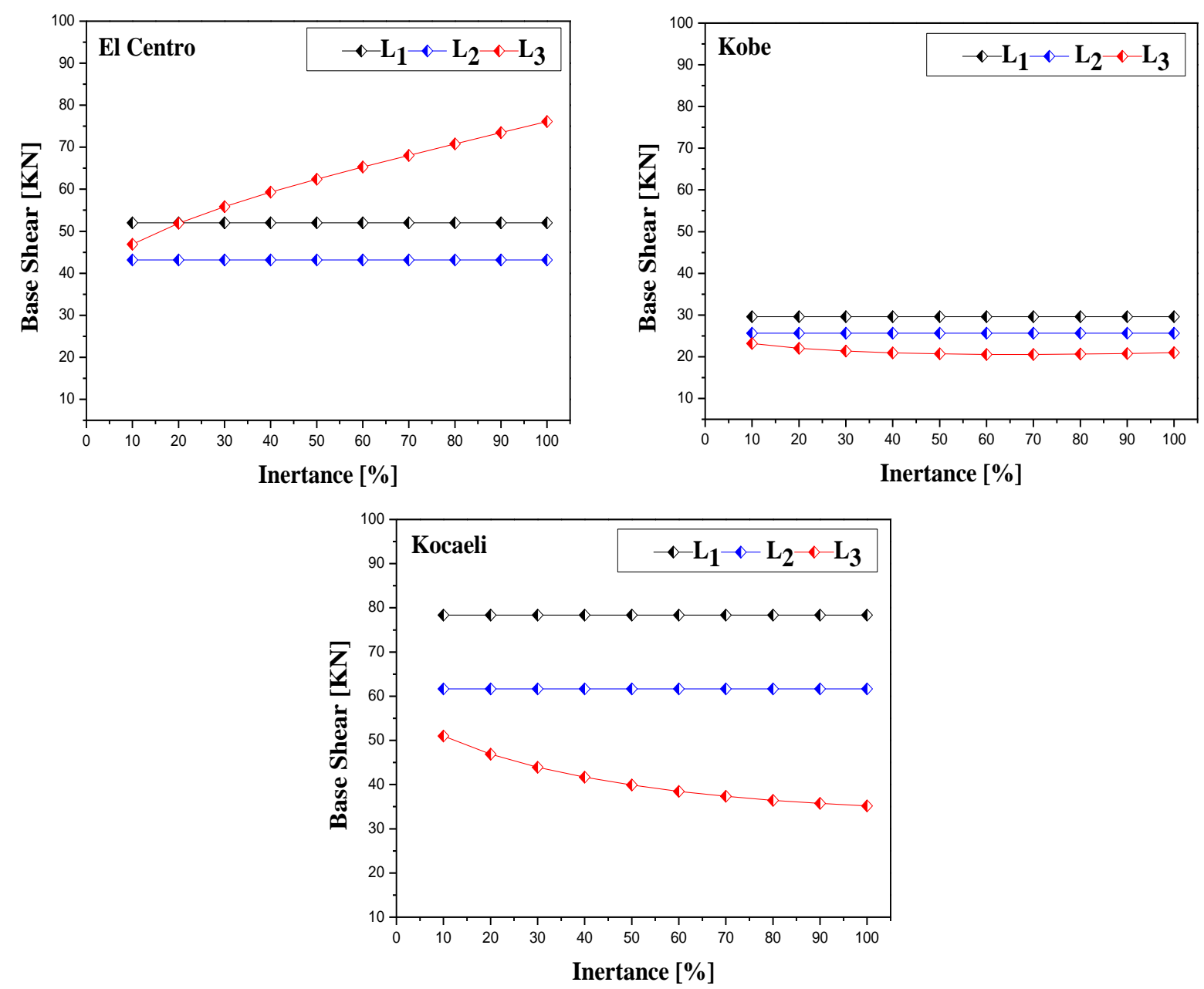

Fig 6. Maximum base shear under El Centro, Kobe, Kocaeli earthquakes

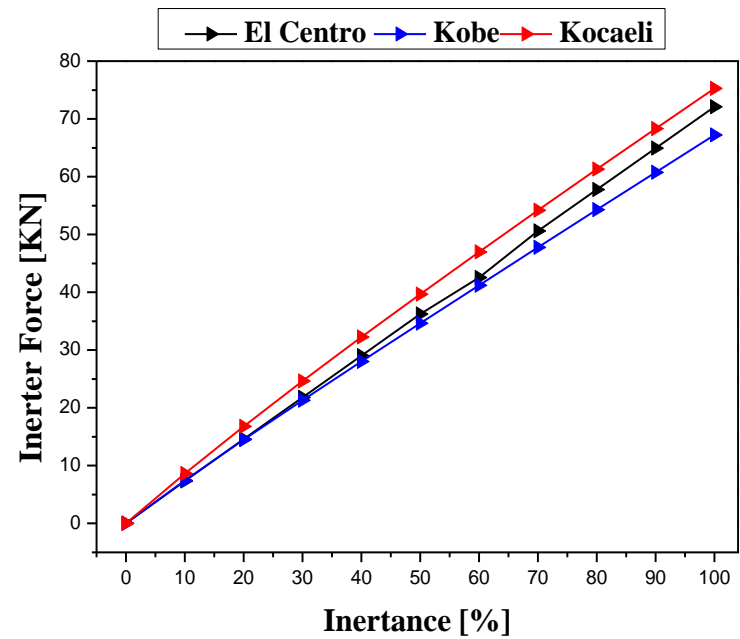

Fig 7. Peak force inerter under El Centro, Kobe, Kocaeli earthquakes 
Based on force equilibrium considerations, the above-discussed stroke reduction is readily attributed to the inerter force, applied to the attached mass. With this in the background, the peak inerter force is plotted as a function of the values of inertance ratio. It is seen that the inerter force rises quickly with the inertance factor against several earthquakes. Where reach the force generated with inerter about $75[\mathrm{KN}]$ under the Kocaeli earthquake.

Fig 7, presents the inerter force relative to the percentage of inertance (\%). The inertance force takes the maximum value of inertance equal to $75[\mathrm{KN}]$ under the Kocaeli earthquake (far-field) and smaller value equal to $67[\mathrm{KN}]$ under Kobe (near-field) earthquake.

\section{Conclusions}

This paper deals with some novel configurations of a so-called tuned-mass-damper-inerter (TMDI) presented by authors to suppress the ground motion such as (base or force excited) placed in a structure combining an inerter device with a conventional tuned mass damper (TMD).

- It is observed that the TMDI composed a simplification of the passive conventional TMD combining a mass amplification inerter device in a supplement to the spring and linear damper elements of the TMD to connect an attached mass to the main building structure.

- The TMDI is more efficient using the same mass/weight of a traditional passive TMD to suppress vibrations near to the natural frequency of the base isolator structure.

- The TMDI gives the possibility of being placed or connected in any floor or story in buildings compared to classical TMD, the last requirement always installed at the top or sometimes at the bottom of the building.

- The novel passive TMDI outperforms the passive conventional TMD, for large values of inertance.

- A new passive TMDI can attain the same field of performance as the conventional passive TMD for significantly less attached mass/weight; this performance is researched for all studied dynamical parameters.

\section{References}

Abdeddaim, M., Kasar, A. A., \& Djedoui, N. (2018). Seismic vibration control using a novel inerto-elastic damper. In MATEC Web of Conferences (Vol. 211, p. 14003). EDP Sciences.

Barredo, E., Larios, J. M., Mayén, J., Flores-Hernández, A. A., Colín, J., \& Montiel, M. A. (2019). Optimal design for high-performance passive dynamic vibration absorbers under random vibration. Engineering Structures, 195, 469-489.

Bekdaş, G., \& Nigdeli, S. M. (2011). Estimating optimum parameters of tuned mass dampers using harmony search. Engineering Structures, 33(9), 2716-2723.

Brzeski, P., Kapitaniak, T., \& Perlikowski, P. (2015). Novel type of tuned mass damper with inerter which enables changes of inertance. Journal of Sound and Vibration, 349, 56-66.

Charrouf, M. E., Djerouni, S., Abdeddaim, M., Djedoui, N., \& Ounis, A. (2019). Combined control strategy for earthquake induced vibrations in structures. $4^{\text {th }}$ Eurasian Conference on Civil and Environmental Engineering (ECOCEE) lstanbul: 13.

De Domenico, D., \& Ricciardi, G. (2018). An enhanced base isolation system equipped with optimal tuned mass damper inerter (TMDI). Earthquake engineering \& structural dynamics, 47(5), 1169-1192.

De Domenico, D., \& Ricciardi, G. (2018). Improving the dynamic performance of base-isolated structures via tuned mass damper and inerter devices: A comparative study. Structural Control and Health Monitoring, 25(10), e2234. 
Deastra, P., Wagg, D. J., \& Sims, N. D. (2018). The effect of a tuned-inerter-damper on the seismic response of base-isolated structures. In 16th European Conference on Earthquake Engineering (pp. 18-21). Sheffield.

Den Hartog, J. P. (1929). Mechanical vibrations in penstocks of hydraulic turbine installations. Transactions of ASME, 101-110.

Djedoui, N., \& Ounis, A. (2014). Tuned Mass Damper For Base Isolated Structures. Sciences \& Technologie. B, Sciences de l'ingénieur, (40), 29-34.

Djerouni, S., Charrouf, M. E., Abdeddaim, M., Djedoui, N., \& Ounis, A. (2019). Optimization of the seismic response of buildings with hybrid control using Tuned Mass Damper (TMD) and base isolation. The First International Conference on Materials, Environment, Mechanical and Industrial Systems, ICMEMIS'19, Djelfa, Algeria.

Elias, S., \& Matsagar, V. (2018). Wind response control of tall buildings with a tuned mass damper. Journal of Building Engineering, 15, 51-60.

Giaralis, A., \& Taflanidis, A. A. (2015). Reliability-based design of tuned mass-damper-inerter (TMDI) equipped multi-storey frame buildings under seismic excitation. In 12th International Conference on Applications of Statistics and Probability in Civil Engineering, ICASP 2015. University of British Columbia Library.

Hadi, M. N., \& Arfiadi, Y. (1998). Optimum design of absorber for MDOF structures. Journal of Structural Engineering, 124(11), 1272-1280.

Hu, Y., \& Chen, M. Z. (2015). Performance evaluation for inerter-based dynamic vibration absorbers. International Journal of Mechanical Sciences, 99, 297-307.

Jia, Y., Li, L., Wang, C., Lu, Z., \& Zhang, R. (2019). A novel shape memory alloy damping inerter for vibration mitigation. Smart Materials and Structures, 28(11), 115002.

Marian, L., \& Giaralis, A. (2017). The tuned mass-damper-inerter for harmonic vibrations suppression, attached mass reduction, and energy harvesting. Smart structures and systems, 19(6), 665-678.

Palazzo, B., \& Petti, L. (1999). Combined control strategy: base isolation and tuned mass damping. ISET Journal of Earthquake Technology, 36(2-4), 121-137.

Shi, Y., Saburi, K., \& Nakashima, M. (2018). Second-mode tuned mass dampers in base-isolated structures for reduction of floor acceleration. Earthquake Engineering \& Structural Dynamics, 47(12), 2519 2538.

Tsai, H. C. (1995). The effect of tuned-mass dampers on the seismic response of base-isolated structures. International journal of solids and structures, 32(8-9), 1195-1210. 